\title{
Geospatial Technologies to Improve Urban Energy Efficiency
}

\author{
Geoffrey J. Hay ${ }^{1}{ }^{*}$, Christopher Kyle ${ }^{1}$, Bharanidharan Hemachandran ${ }^{1}$, Gang Chen ${ }^{1}$, \\ Mir Mustafizur Rahman ${ }^{1}$, Tak S. Fung ${ }^{2}$ and Joseph L. Arvai ${ }^{3,4}$
}

1 Foothills Facility for Remote Sensing and GIScience, Department of Geography, University of Calgary, 2500 University Drive N.W., Calgary, AB T2N 1N4, Canada;

E-Mails: cdkyle@ucalgary.ca (C.D.K.); hbharani@ucalgary.ca (B.H.); gangchen@ucalgary.ca (G.C.); mmrahm@ucalgary.ca (M.M.R.)

Information Technologies, University of Calgary, 2500 University Drive N.W., Calgary,

AB T2N 1N4, Canada; E-Mail: tfung@ucalgary.ca

3 Institute for Sustainable Energy, Environment, and Economy \& Haskayne School of Business, University of Calgary, 2500 University Drive N.W., Calgary, AB T2N 1N4, Canada;

E-Mail: arvai@ucalgary.ca

4 Decision Research, 1201 Oak Street, Eugene, OR 97401, USA

* Author to whom correspondence should be addressed; E-Mail: gjhay @ucalgary.ca

Tel.: +1-403-220-4768; Fax: +1-403-282-6561.

Received: 1 May 2011; in revised form: 23 June 2011 / Accepted: 27 June 2011 /

Published: 5 July 2011

Abstract: The HEAT (Home Energy Assessment Technologies) pilot project is a FREE Geoweb mapping service, designed to empower the urban energy efficiency movement by allowing residents to visualize the amount and location of waste heat leaving their homes and communities as easily as clicking on their house in Google Maps. HEAT incorporates Geospatial solutions for residential waste heat monitoring using Geographic Object-Based Image Analysis (GEOBIA) and Canadian built Thermal Airborne Broadband Imager technology (TABI-320) to provide users with timely, in-depth, easy to use, location-specific waste-heat information; as well as opportunities to save their money and reduce their green-house-gas emissions. We first report on the HEAT Phase I pilot project which evaluates 368 residences in the Brentwood community of Calgary, Alberta, Canada, and describe the development and implementation of interactive waste heat maps, energy use models, a Hot Spot tool able to view the 6+ hottest locations on each home and a new HEAT Score for inter-city waste heat comparisons. We then describe current challenges, lessons learned and new solutions as we begin Phase II and scale from 368 to 300,000+ 
homes with the newly developed TABI-1800. Specifically, we introduce a new object-based mosaicing strategy, an adaptation of Emissivity Modulation to correct for emissivity differences, a new Thermal Urban Road Normalization (TURN) technique to correct for scene-wide microclimatic variation. We also describe a new Carbon Score and opportunities to update city cadastral errors with automatically defined thermal house objects.

Keywords: urban energy efficiency; geospatial; TABI; GEOBIA; thermal imaging; waste heat; Geoweb; Google Maps; hot spots; TURN; emissivity modulation; HEAT Score

\section{Introduction}

In Canada, buildings account for $\approx 35 \%$ of all emitted green house gasses (GHG), use $33 \%$ of Canada's total energy production and consume $50 \%$ of Canada's natural resources, of which the majority is used for space and water heating. Space heating provides one of the best opportunities for energy cost savings; however, the most cited obstacle to energy efficiency improvements is a lack of interest [1]. This is little surprise when one considers what does energy efficiency really look like? Where is it located, and how do residents know that their home (not the energy saving devices inside) is energy efficient?

It has recently been shown that effective feedback increases public awareness and helps to significantly reduce energy consumption [2]. This is increasingly supported by numerous commercially available energy monitoring devices [3], and a recent letter to the President of the United States by a consortium of 47 industrial partners requesting that his Administration adopt policy to provide every American household actionable information on their energy use [4]. From a remote sensing perspective, one method to improve energy efficiency is to use a thermal sensor to identify temperature anomalies, i.e., 'Hot Spots' in existing infrastructure where 'waste heat' is leaving the system and to correct for them. Thermal infrared (TIR) remote sensing or Thermography has been used since World War II to provide valuable tactical and environmental surveillance information, animal counts, wild-fire spotting, electrical power line surveys, aid in search and rescue operations and recently to help track pandemic flu. When combined with an airborne and or satellite platform, its uses also include: (i) land cover classifications; (ii) urban heat island analysis; (iii) residential heat loss/waste heat mapping; and (iv) roof moisture surveys [5-7] of which the latter is becoming an increasingly useful and important tool in the multi-billion dollar (USA) roof maintenance industry $[8,9]$. In 2000, the total infrared imaging systems market generated revenues of $\$ 1.82$ billion and by 2008 it was predicted to reach $\$ 2.82$ billion. Airborne systems accounted for $89.8 \%$ of this market in 2000 , and were predicted to account for $83.3 \%$ of the market by 2008. In 2000, commercial airborne TIR imaging systems generated revenues of $\$ 17.5$ million, and were estimated to reach $\$ 34.2$ million by 2008 [10].

In winter 2000 and 2007, the London Borough of Haringey conducted aerial TIR heat loss surveys to provide residents with an idea of the energy efficiency of their homes. In 2001, the city of 
Aberdeen, Scotland, conducted a similar project, as did Exeter in 2009. In the 2007 and 2009 surveys, the thermal data were published online as very simple temperature maps, with almost no opportunity for user interaction or feedback [11]. Additionally, the 2007 heat loss survey suffered from serious calibration problems due in-part to: (i) the scene being captured on film (as many 100s of TIR air photos) then being scanned, digitized, geocorrected and mosaiced; and (ii) the scene being acquired over multiple dates, with temperatures changing between flights lines. This resulted in the City Council claiming a refund for their project costs, as the resulting heat maps were unusable [12].

Since this time, there have been significant advances in TIR technology [7], and in open-source web-based technologies that incorporate both geographic and non-spatial information [13]. Collectively, these web-enabled technologies are referred to as the Geospatial web or the Geoweb [14]. Most critical to its success are advances in Open Geospatial Consortium (OGC) and Digital Earth standards [15], powerful virtual globe software popularized by Google Earth, Microsoft's Bing Maps and NASA World Wind, along with more recent tools such as the PYXIS Digital Earth Reference Model, which form a common data structure to formalize the Geoweb, where '... location is used to organize and integrate the flow of information for rapid knowledge creation and evidence based decision making...' [16], ultimately resulting in new geospatial intelligence (i.e., content in geospatial context) [17]. From a remote sensing perspective, Geoweb platforms that build on high resolution imagery and maps also provide a powerful platform for visual accuracy assessment, which is an important step towards improving remote sensing science [13]. Examples range from Ushahidi for crisis response [18], to the Web Fire Mapper which integrates remote sensing and GIS technologies to deliver global MODIS hot spot/fire locations [19].

With the goal to improve urban energy efficiency by integrating geospatial technologies that provide effective user feedback, we report on the HEAT (Home Energy Assessment Technologies) Phase I pilot project. HEAT is a FREE Geoweb mapping service, designed to help residents improve their home energy efficiency by visualizing the amount and location of waste heat leaving their residences and communities as easily as clicking on their house in Google Maps. HEAT incorporates Geospatial solutions for residential waste heat monitoring using Geographic Object Based Image Analysis (GEOBIA) [20], Canadian built TABI (Thermal Airborne Broadband Imager) technology and a web delivery system using Google Maps as the front-end. A back-end geospatial information system provides users with timely, in-depth, easy to use, location-specific waste-heat information; as well as opportunities to save their money and reduce their green house gas (GHG) emissions. The mission of HEAT is '...to show what urban energy efficiency looks like, where it is located, what it costs and what to do about it. We believe that if people could see the waste heat they generate and if they knew how much it 'cost' (financially and to the environment), that they would want to take action. We want to show them how. Ultimately, our vision is to empower the urban energy efficiency movement by providing free, accurate and regularly updated waste heat solutions for the world...'.

To develop this vision, the following sections provide details on (2.1) the Phase I study area and preprocessing of the TABI 320 data, including (2.2) emissivity and (2.3) geometric corrections. This is followed by (3.0) the Methods section which describes (3.1) the HEAT platform design, and (3.2) the methods used to provide the HEAT user experience - including HEAT Maps, fuel tables, energy use models, a Hot Spot detection tool, and a new HEAT Score (Sections 3.2.1-3.4). We then describe current challenges, lessons learned and new solutions in the (4.0) Discussion section, as we begin 
Phase II and prepare to use the TABI-1800 to scale from 368 to 300,000+ homes. Specific topics include: (4.1) TABI limitations and solutions for large area TIR urban imaging, (4.2) a new object-based mosaicing (OBM) strategy, (4.3) an application of Emissivity Modulation to correct for scene-wide emissivity differences, (4.4) a new Thermal Urban Road Normalization (TURN) technique to correct for scene-wide microclimatic variation, (4.5) challenges with HEAT and Carbon Scores, and (4.6) opportunities to update city cadastral errors with automatically defined GEOBIA thermal house objects. We then summarize our findings in (5.0) the Conclusion section.

\section{Study Area and Data Preprocessing}

\subsection{Study Site and TABI-320 Data}

The HEAT Phase I pilot is located in the Brentwood community of Calgary, Alberta Canada where it includes 368 residential buildings built between 1961 and 1965, suggesting that they are likely candidates for energy saving renovations. A corresponding $600 \times 2,000$ pixel TABI-320 geometrically corrected (two flight-line) mosaic (Figure 1), with a $1.0 \mathrm{~m}$ spatial resolution and a $0.1{ }^{\circ} \mathrm{C}$ thermal resolution was acquired at $1,000 \mathrm{~m}$ (above ground level) under clear night-time skies by ITRES Research Limited on 24 July 2006 at 04:00-Mountain Standard Time (MST). The TABI-320 is a pushbroom thermal infrared sensor sensitive to the $8 \mu \mathrm{m}-12 \mu \mathrm{m}$ range of the electromagnetic spectrum that produces an image 320 pixels wide [21]. This sensor also contains flight information that is later used to geo- and ortho-correction imagery to a nominal spatial resolution of (+/-) 2 pixels.

Figure 1. This image provides an overview of the full TABI 320 (two flight-line) mosaic of the Brentwood Community (at $1.0 \mathrm{~m}$ and $0.1{ }^{\circ} \mathrm{C}$ resolutions) (A). The red box in (A) represents the entire zoomed section shown in $(\mathbf{B})$. The red-box in $(\mathrm{B})$ provides further details as found in (C). Dark (cold) rectangular objects represent homes and garages, surrounded by white (hot) roads and (warm) grey yards. Vehicles are also visible in the street as small dark rectangles.

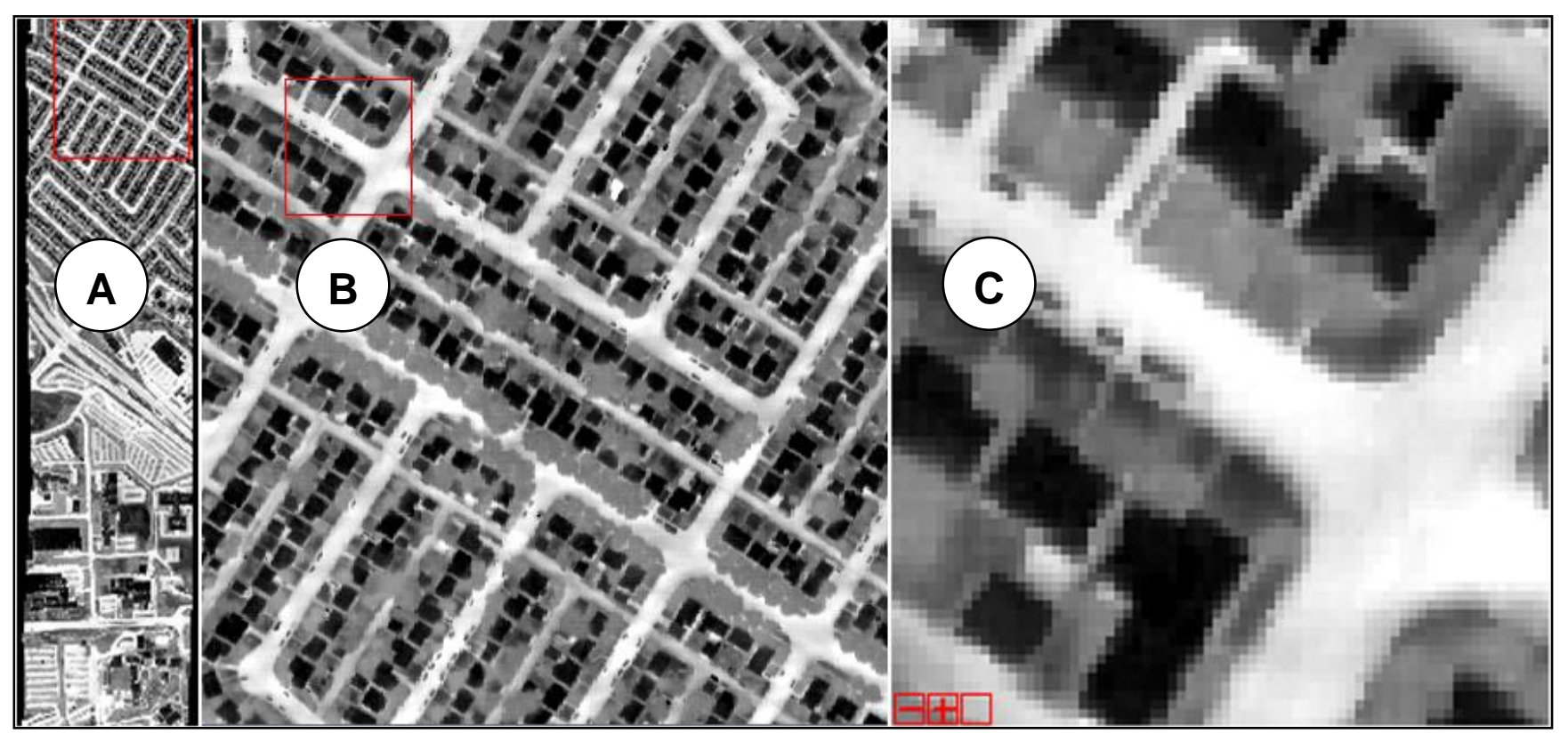


Due to the relatively small size of this study area, and the favorable climatic conditions at the time of data acquisition, no atmospheric corrections were applied; however, we note that Section 4 describes a number of new climate and flight-line normalization procedures under development for a larger, full City of Calgary TABI-1800 data acquisition $(25 \mathrm{~km} \times 35 \mathrm{~km})$.

\subsection{Emissivity Corrections}

Once acquired, the TABI image was pre-processed by ITRES to a general emissivity $(\varepsilon)$ of 0.94 and provided for our analysis. TIR sensors generally record apparent radiant temperature rather than true kinetic temperature. To obtain 'true' temperature the data needs to be corrected for $(\varepsilon)$; which is defined as the ratio between the actual radiance emitted by the object and the blackbody radiance at the same temperature [22]. Essentially, $(\varepsilon)$ is a measure of a material's ability to radiate absorbed energy. Once received from ITRES, the imagery were converted to raw values, and an $(\varepsilon)$ of 0.91 was applied to correct the dataset to the (general) kinetic temperature of asphalt shingles [23]; which constitute $100 \%$ of the roof type in this study area (Section 4.5). As a result, temperature values displayed for each roof represent their true (kinetic) temperatures values $\left( \pm 0.1{ }^{\circ} \mathrm{C}\right)$, from which a number of different waste heat attributes are calculated (Section 3.2). We define waste heat as any house/roof temperature greater than the nominal ambient air temperature recorded at the time of thermal data acquisition, which in this case was provided by ITRES as $0{ }^{\circ} \mathrm{C}$. If a different ambient temperature value were recorded, waste heat would simply be calculated as defined in Equation (1), and used in the corresponding maps and models (Section 3).

$$
\text { Waste Heat }=\text { House Temperature }- \text { Ambient Temperature }
$$

Waste heat represents (expensive) heated air that is leaving a home, instead of remaining to heat the living envelope. It typically escapes through poorly insulated doors, windows, walls, ceilings, ductwork and electrical fixtures (i.e., pot lights). This is costly to the home owner, generates considerably more GHG emissions than necessary, and is invisible to the human eye.

\subsection{Geometric Corrections}

A July 2006, $30 \mathrm{~cm}$ color (RGB) orthophoto mosaic was also used in conjunction with (2007) City of Calgary cadastral polygons (i.e., homes, land parcels and roads) to geocorrect the TIR image to a $1.0 \mathrm{~m}$ spatial resolution [root mean square error (RMSE) < 1.207]. This was based on: (i) selecting 286 ground control points; (ii) applying a Nearest Neighbor interpolation with a 4th-order polynomial warping; and (iii) visually checking the resulting image for consistency. We note that prior to geocorrection, the cadastral polygons were also overlaid on the RGB image, revealing an exact visual fit, which suggested that they had been created by the city from the same dataset. Attribute data related to house age, area, and construction type were also provided as part of the cadastral dataset. In general, the original TIR image well matched the provided polygons, except in areas along the mosaic seam where the shapes of numerous houses appeared to be cut, or portions were missing. Correcting for these required the (previously mentioned) high-order polynomial warping. To ensure that the fit between vectors and raster data was consistent during image processing we developed: (i) shape checking metrics to evaluate raster $v s$. vector object 'fit' (see Section 3.3); and (ii) an object-centric 
approach to improve the mosaic process (see Section 4.2).

We also note that the entire project has been developed to work with the TABI data as the sole data source. This is in the event that it is not possible to obtain corresponding cadastral polygons and their associated attribute data (e.g., age, building type, etc.). However, if cadastral data are available, then both can be incorporated into the image-processing workflow (Section 3.1) to produce an enhanced product (Section 3.3).

\section{Methods}

In this section we describe: (i) the HEAT Geoweb architecture; (ii) the user experience and system functionality; and (iii) provide details for generating Hot Spots and HEAT Scores. It is important to note that as part of the Phase I development, we have developed the HEAT Geoweb service to work with a large city dataset; however, due to the relatively small size of the Brentwood study site, we have generated our own Brentwood 'pseudo' city and (North, Central and South) community boundaries (which follow roads). Additionally, due to the multi-partner investments and commercial potential of this project, certain methodological details have been withheld.

\subsection{Platform Design}

The HEAT Geoweb architecture was developed in-house and is based on OGC standards and includes: (i) an image processing pipeline; (ii) a geospatial database; (iii) a web server platform capable of running server side scripting languages; and (iv) an AJAX supported web browser. Figure 2 illustrates the overall layout and interconnections from the initial image processing, to the end users mobile device or AJAX supporting web browser.

Home owners are able to connect to the HEAT web site which pulls data from a secured web server running custom CGI scripts written in Python. These python scripts parse the end-user's requests and retrieve the relevant information from the PostgreSQL/PostGIS database which has previously been filled with image processing results. Once the requested data are returned from the database, they are passed back to the end user by the python scripts. This geospatial information is then displayed on the HEAT web site where home owners can interact with it and further evaluate their house, community and city in detail (see Section 3.2).

Figure 2. Overview of the HEAT processing pipeline.

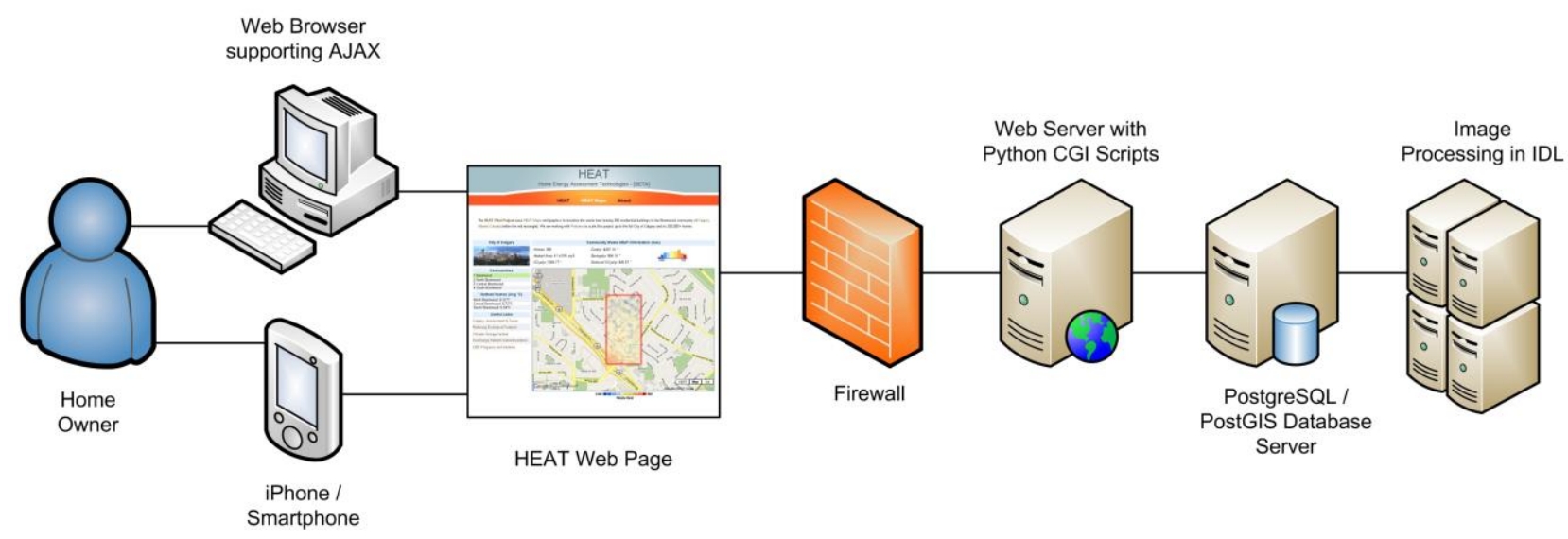


A combination of PostgreSQL and PostGIS provide the geospatial database backend to the HEAT web service. PostgreSQL is an object-relational database management system (ORDBMS). PostGIS provides support for geographic objects to the PostgreSQL. Open source geospatial libraries (such as GDAL/OGR for raster and vector file handling, and PROJ.4 for coordinate system conversion) are used within the image processing pipeline. Image processing is conducted using ENVI and IDL (Environment for Visualizing Images and Interactive Data Language-Remote Sensing and image analysis software), with feature extraction based on a combination of in-house and commercial GEOBIA software (i.e., eCognition and ENVI-EX). GEOBIA combines segmentation, spatial, spectral and geographic information extraction along with analyst experience derived from image-objects in order to model geographic entities [20]. Image-objects are groups of pixels in the image that represent meaningful objects in the scene (i.e., a house, streets, etc.). Apache web server provides a secure, efficient and extensible HTTP service. Python, a server side scripting language is used to serve the requests from the user back to the web browser. The Google Maps API on a web browser serves as the user interface for the system. The Google Maps API provides an application programming interface for using Google Maps on any website. Interaction with a Google Map is sent to the server for processing. Python processes the requests and sends back the response in JSON format. JASON (JavaScript Object Notation) is a lightweight data-interchange format. Javascripts on the browser interpret and displays the response back to the user interface. Except for ENVI, IDL and eCognition all other software used is free and open source [24]. Though we note that GDL [25], a GNU version of IDL is freely available, as are numerous segmentation software, both online [26], and as described by Neubert et al. [27].

\subsection{The HEAT User Experience}

Based on location-aware web services and high resolution airborne TIR imagery, the HEAT pilot project provides a host of interactive tools for advanced spatial decision making, that are applicable through a range of scales from the individual home owner, the community, to an entire city. To achieve this, the HEAT graphical user interface (GUI) is developed based on the Landscape Ecology principles of Hierarchy Theory [28] that recognize the relationships and flows of multiple components through scale. Thus, at any one time, two or three levels of residential information can be visible to the user to simultaneously provide an urban and a community geo-spatial context. To understand how these tools may be used, the following sections describe a typical user experience with: (i) HEAT Maps; (ii) Energy Use Models; (iii) Hot Spots; and (iv) the HEAT Score.

\subsubsection{HEAT Maps}

When a user first enters the HEAT Maps page (Figure 3(A-E)) they are met with a graphical interface composed of images, maps, and statistics. Figure 3(A) shows an image of the City of Calgary. Figure 3(B) depicts the city HEAT Score which represents a measure of the overall waste heat of all homes in the city (Section 3.4). Figure 3(C) describes: (i) the total number of homes in the pseudo 'city'; (ii) the total heated area; (iii) the CO2e (Carbon Dioxide equivalent) generated using a specific fuel type for space heating (in this case electricity from coal), along with (iv) the estimated yearly cost for the entire community. This is followed by (v) the estimated yearly savings (\$), (vi) the 
estimated reduction in $\mathrm{CO} 2 \mathrm{e}$ if the city were able to implement methods to reduce the waste heat of all its homes for a specific fuel type (Section 3.2.4), and (vii) a histogram of the number of homes divided into 10 natural temperature breaks (Section 3.2.2).

Figure 3. The HEAT Maps page illustrates (A) an image of the city, (B) the city HEAT Score, (C) City statistics, (D) Community statistics and (E) a smooth interpolated City Heat Map that models the overall residential waste-heat distribution within the city.

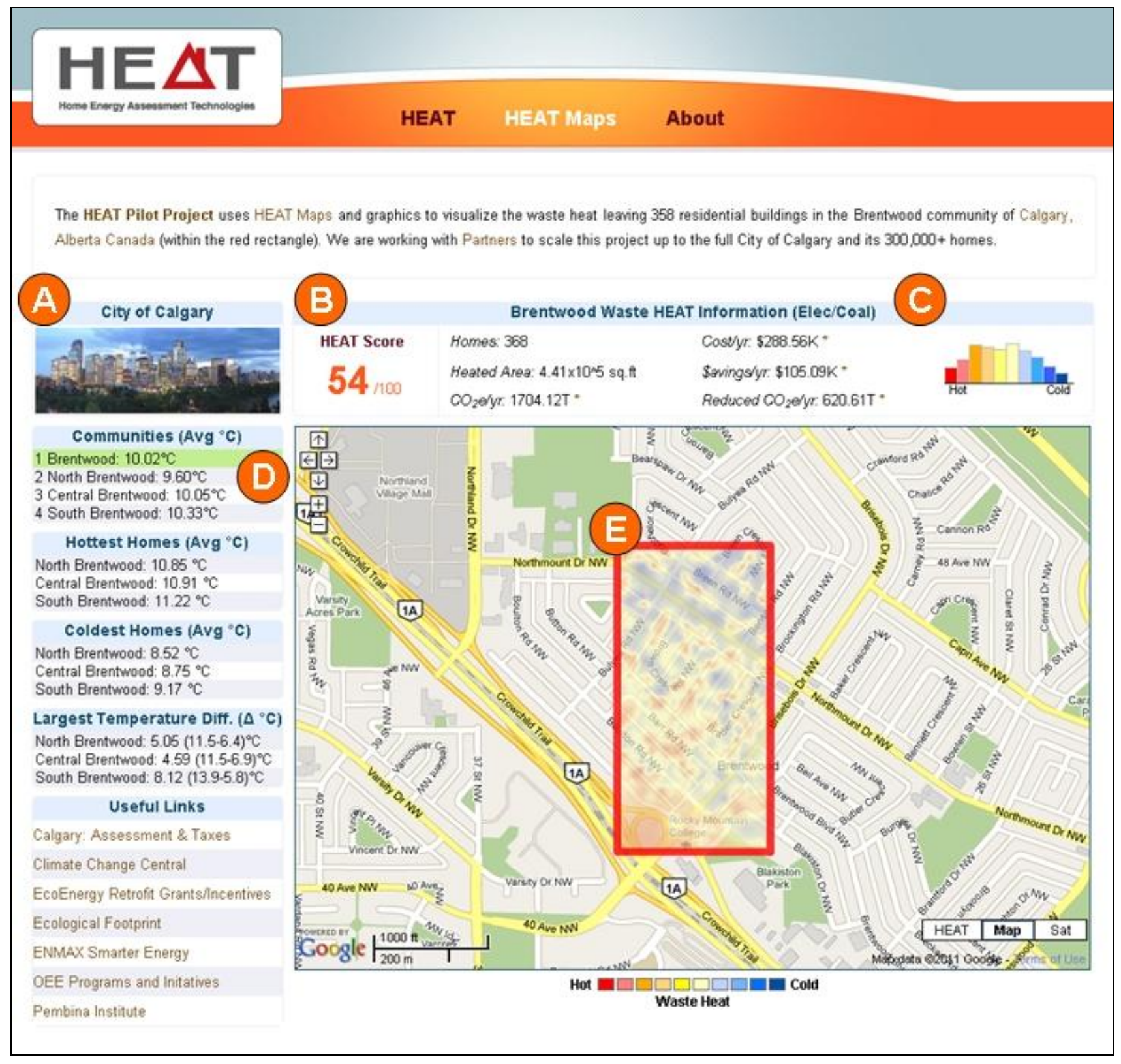

As a user mouses over the different communities (Figure 3(D)), the corresponding statistics are also updated for the respective community. These are based on the average roof-top temperature for each home within a specific community, and include information on the hottest and coldest homes, as well as the homes with the greatest temperature variability. Figure 3(E) illustrates a smooth interpolated City Heat Map that models the overall residential waste-heat distribution of the Brentwood 'pseudo' city. Interpolation is based on Kriging the average roof temperature for each home in the city, and is 
presented only to provide a quick visual summary of the entire 'city' (within the red-rectangle) ranging from hot areas (red) to cool areas (blue). Kriging is a geospatial technique that generates an estimated surface from a scattered set of points, and is synonymous with 'optimal prediction' in space using observations taken at known nearby locations [29].

\subsubsection{Community HEAT Maps}

Clicking inside the red-rectangle will zoom into the Community HEAT Map (Figure 4(A,B)) which displays individual house polygons classified into 10 temperature classes based on their average roof top temperature (Figure 4(A)). Classification is based on the Natural Jenks method, which determines the 'best' arrangement of class values by reducing the within-class variation and increasing the between-class variation [30]. A histogram showing the frequency of these same (average roof) temperatures provides a useful summary of the thermal distribution of homes within a community. This HEAT map also provides a community based HEAT Score (see Section 3.4 for details) along with associated energy use, $\mathrm{CO}_{2} \mathrm{e}$ statistics and potential savings (Figure 4(B)). Table 1 provides a summary of all community waste heat statistics, with Brentwood representing the combined total of the other three communities.

Figure 4. The Community Heat Map shows individual homes (i.e., colored polygons) in 10 color classes based on their average roof top temperature. This example shows homes within the Central Brentwood Community (green highlight) defined by the red community boundaries (A). Location-based community waste heat statistics are also provided (B).

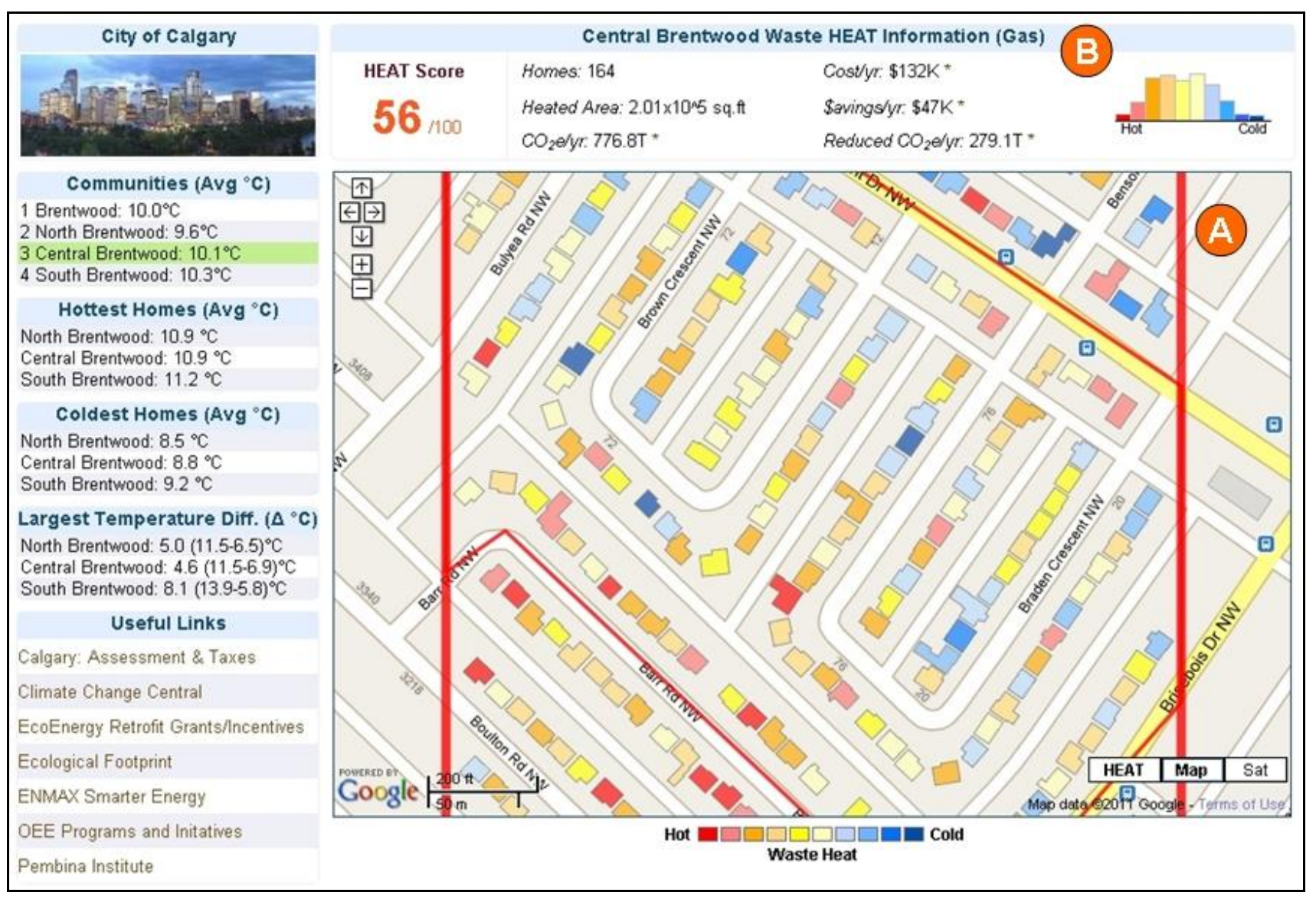


Table 1. Summary of Community Waste Heat Statistics.

\begin{tabular}{|c|c|c|c|c|c|c|c|}
\hline Community & $\begin{array}{c}\text { No of } \\
\text { Houses }\end{array}$ & $\begin{array}{c}\text { Heated Area } \\
\left(10^{5} \text { sq.ft }\right)\end{array}$ & $\begin{array}{c}\mathrm{CO}_{2} \mathbf{e} \\
(\mathbf{T})\end{array}$ & $\begin{array}{l}\text { Reduced } \\
\mathrm{CO}_{2} \mathrm{e}(\mathrm{T})\end{array}$ & $\begin{array}{c}\text { Cost } / \mathbf{y r} \\
\left(\$ 10^{3} \mathrm{CAD}\right)\end{array}$ & $\begin{array}{l}\text { Savings/yr } \\
\left(\$ 10^{3} \mathrm{CAD}\right)\end{array}$ & $\begin{array}{c}\text { Histogram } \\
\text { (house temp }{ }^{\circ} \mathbf{C} \\
\text { distribution) }\end{array}$ \\
\hline $\begin{array}{c}\text { Brentwood } \\
\text { (total of all } \\
\text { communities) } \\
\end{array}$ & 368 & 4.41 & 1704.1 & 620.6 & 288.6 & 105.1 & \\
\hline $\begin{array}{c}\text { North } \\
\text { Brentwood }\end{array}$ & 95 & 1.17 & 452.1 & 199.5 & 76.6 & 33.8 & \\
\hline $\begin{array}{c}\text { Central } \\
\text { Brentwood }\end{array}$ & 164 & 2.01 & 776.7 & 279.1 & 131.5 & 47.3 & Cold \\
\hline $\begin{array}{c}\text { South } \\
\text { Brentwood }\end{array}$ & 109 & 1.23 & 475.2 & 142.0 & 80.8 & 24.1 & \\
\hline
\end{tabular}

\subsubsection{Home HEAT Maps}

Clicking on a classified house polygon in the Community HEAT Map will display the corresponding Home HEAT Map (Figure 5(A-G)). This map provides a detailed TABI waste heat signature for a specific home, with roof temperatures automatically shown when moused over (Figure 5(A)). In this example, the three hottest roof top locations (referred to as Hot Spots) are automatically defined and represented as three colored circles (Figure 5(B)), with their accompanying color-coded temperature values (Figure 5(C)). By clicking on the arrows [located at (Figure 5(C))] the top 6 Hot Spots, their temperature values and locations will be cycled through, allowing the user to visualize them within a house-context. In total, 6 interior, and 6 exterior (i.e., roof-edge) Hot Spots are calculated for each home, but only the top three Hot Spots are shown at a time. This allows a home owner to evaluate whether a Hot Spot represents the chimney, vent or some other roof object or area of interest.

Our experience has shown that exterior roof Hot Spots typically correspond to heat escaping from the doors and windows beneath them or from problem roof areas. These can be confirmed by clicking on the Street View icon (Figure 5(D)). When, clicked, the residential heat map divides to allow the corresponding Google Street View image to appear on its right hand side (Figure 5(E)). Users can then zoom and pan around the Street View image which provides visual evidence of Hot Spot locations. Alternatively, users can move their location in the residential heat map (Figure 5(F)), which automatically updates their Street View perspective. In this example, a cursory visual comparison of the Hot Spots (Figure 5(B)) and the Street View image (Figure 5(E)) reveals that waste heat is escaping between the main home structure and the smaller front addition. To further evaluate this scene, the user can also click on the 'Sat' button (bottom middle of Figure 5) and view the house polygons overlaid on the corresponding Google satellite or aerial imagery (not shown), rather than in their current map view. 
Figure 5. The Home Heat Map provides a thermal image of an individual home showing: (A) the moused-over roof temperature, (B) three Hot Spots and (C) their associated temperatures, (D) the Google Street View icon linked to (E) the corresponding house Street View. (F) shows the map location of the evaluated house. (G) defines the Fuel Table, the associated fuel sources, the heating costs/day $(\$)$ and the resulting $\mathrm{CO}_{2} \mathrm{e}(\mathrm{kg})$. Visual analysis of the Hot Spot locations (B) compared to the Street View image (E) reveal that heat is escaping between the main home structure and the smaller addition (front right).

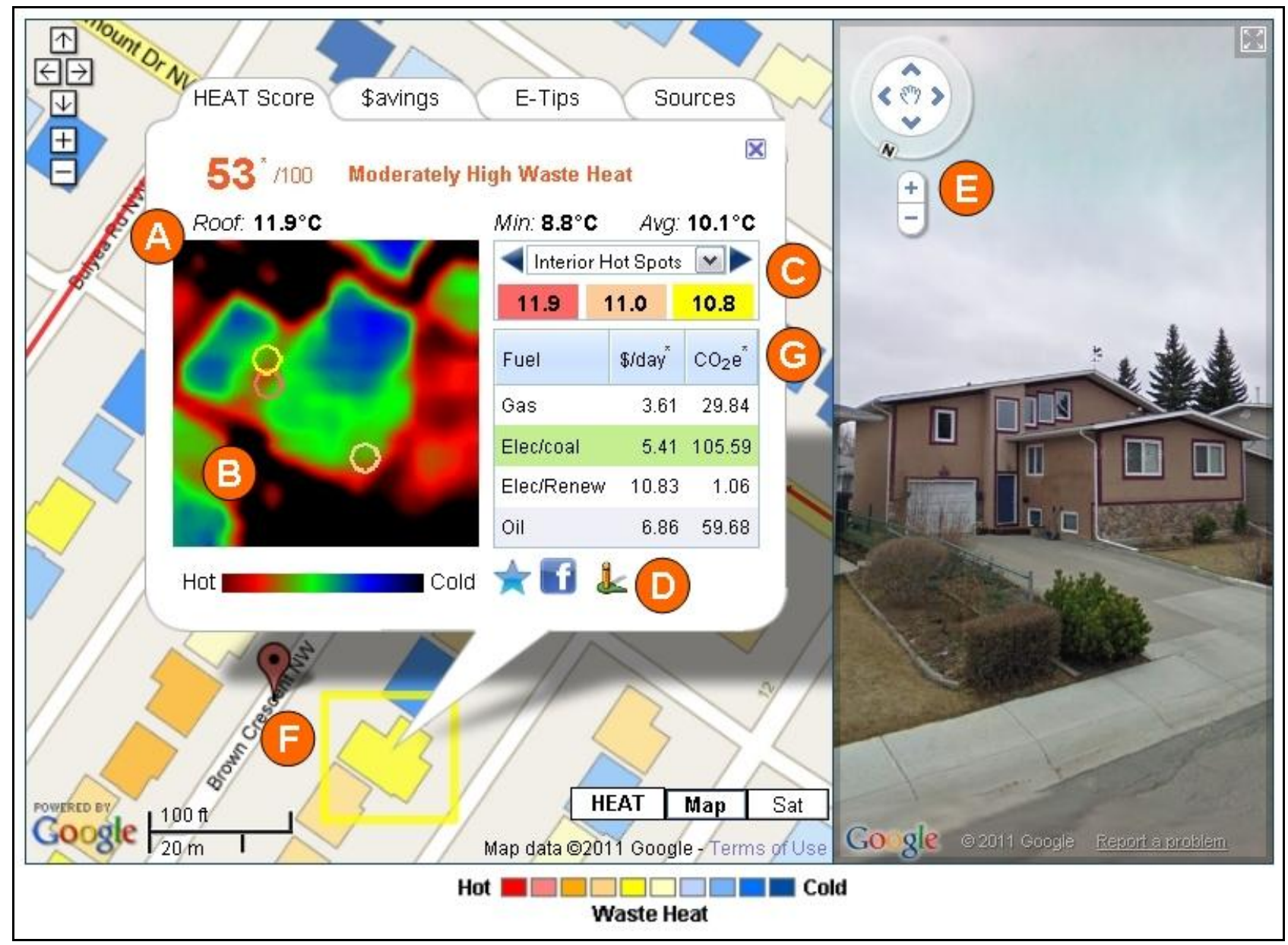

\subsubsection{The Fuel Table}

In the Fuel Table (Figure 5(G)), the (\$) cost per day of heating the home, along with estimated $\mathrm{CO}_{2} \mathrm{e}(\mathrm{kg})$ for different geographically relevant fuel types (i.e., gas, oil, wind and hydro electricity, etc.) are also modeled. These values are calculated based on (three years of) sample house data which consists of the above-ground living area of the home, the natural gas (and electricity) used for space heating per month, and the age and construction type of the home. Combined with Canmet Energy models developed for the City of Calgary [31], these data are used to model the cost and quantity of energy required for space heating all study site houses per day-weighted by their area and age (based on City cadastral data). The Green House Gas emissions per day for $\mathrm{CO}_{2} \mathrm{e}$ are calculated based on this home energy use model, and on $\mathrm{CO}_{2}$ e coefficients provided from a recent Canadian energy mapping study [1]. This study provides the $\mathrm{CO}_{2} \mathrm{e}$ coefficients generated for natural gas, and electricity from 
coal. In the absence of GHG coefficients for other fuel sources, the $\mathrm{CO}_{2} \mathrm{e}$ coefficient for oil is calculated as a factor of the GHG coefficient of gas, and the $\mathrm{CO}_{2} \mathrm{e}$ coefficient of electricity from renewable resources is calculated as a factor of the GHG coefficient of electricity from coal. In this example (Figure 5(G)), electricity generated from coal is highlighted in green. When double clicked, the view moves from the HEAT Score tab, to the \$avings Tab, revealing the Annual Home Energy Use Model (Figure 6(A-F)).

\subsubsection{The Annual Home Energy Use Model}

Based on sample house data (described in Section 3.2.4) and a specific local fuel type selected by the user (Figure 6(A)), the Annual Home Energy Use Model provides a yearly estimate of the money saved (Figure 6(B)) and the reduced $\mathrm{CO}_{2} \mathrm{e}$ (Figure 6(C)) if a home owner lowered their waste heat (after correcting for the roof material emissivity-Section 2.2), from the maximum (Figure 6(D)), to the minimum (Figure 6(E)) roof temperature (as defined for their house in the Home HEAT Map-Figure 5). In this example (Electricity from Coal), it is estimated that a home owner could save $\$ 522$ and reduce their annual $\mathrm{CO}_{2} \mathrm{e}$ contribution by 10.2 tons, if they reduced their waste heat from $11.9^{\circ} \mathrm{C}$ to $8.8^{\circ} \mathrm{C}$.

As previously indicated, all house temperature measurements above the ambient air temperature are considered as waste heat. For this energy use model, the target waste heat temperature is not based on reaching the ambient temperature, which would only be the case if the home had a perfectly insulated living envelope and well performing attic ventilation (Section 4.6), or if the home's heating systems were completely turned off for an extended period of time. Instead, our objective is to have users apply energy efficiency enhancements (defined in the E-Tips tab-Figure 6(F)) to bring the maximum roof top temperature, to the existing minimum temperature. Conceptually this is a reasonable expectation, as the minimum roof temperature has already been reached at one or more roof locations (Figure 5(C)). Savings are calculated as the difference between the actual cost (assumed to be based on the maximum roof top temperature) and the cost calculated as a function of the observed minimum roof top temperature (Equation (2)).

$$
\begin{gathered}
\text { Savings }=\text { Total Cost }-(\text { Total Cost } \times \\
\text { Minimum roof temperature/Maximum roof top temperature })
\end{gathered}
$$

Similarly, $\mathrm{CO}_{2} \mathrm{e}$ reductions are calculated as the difference between the emission, and the $\mathrm{CO}_{2} \mathrm{e}$ emission calculated as a function of the minimum observed roof top temperature (Equation (3)).

$$
\begin{gathered}
\mathrm{CO}_{2} \mathrm{e} \text { Reductions }=\text { Total } \mathrm{CO}_{2} \mathrm{e}-\left(\text { Total } \mathrm{CO}_{2} \mathrm{e} \times\right. \\
\text { Minimum roof temperature/Maximum roof top temperature })
\end{gathered}
$$

In the E-Tips tab (Figure 6(F)), energy efficiency information to assist in this goal will be provided such as sealing obvious draught areas, improving living-envelop insulation, and improving the energy efficiency of windows and doors, etc. More specialized information related to locally available HVAC (Heating, Ventilating, and Air Conditioning) systems and service providers, alternative energy sources-both off the grid (i.e., geothermal, wind, solar, tide, etc.) - and from (green) energy providers, to NetZero construction [32] and LEED (Leadership in Energy and Environmental Design) [33] certification for new and existing construction will also be provided. 
Figure 6. The \$avings tab illustrates (A), the Annual Home Energy Use Model which provides a yearly estimate of $(\mathbf{B})$, the money saved and $(\mathbf{C})$, the resulting $\mathrm{CO}_{2} \mathrm{e}$ reductions if a home owner is able to reduce their waste heat from (D), the maximum to (E), the minimum roof temperature based on energy efficiency information located in E-Tips (F).

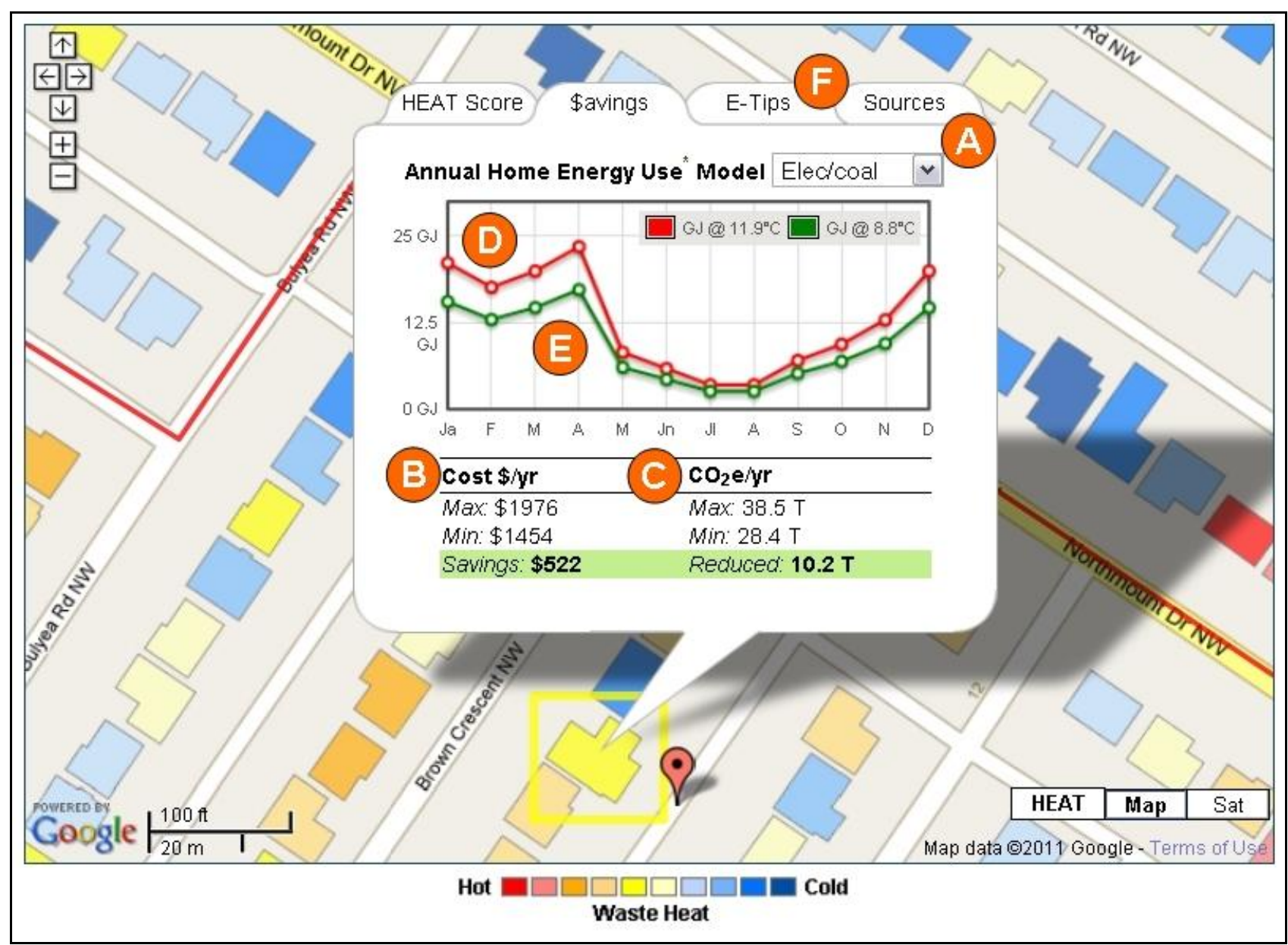

\subsection{Generating Hot Spots}

The process of generating Hot Spot locations and statistics for individual houses begins with the input of either thermal raster imagery alone, or both raster and vector data (Figure 7(1-6)). Thermal imagery (Figure 7(1a)) is always required as an input, as it is the primary temperature source being evaluated. The optional vector data represents building footprints (Figure 7(1b)), which if available, is very useful. Without access to city cadastral polygons, GEOBIA feature extraction algorithms are used to define individual house objects for the entire scene (Figure 7(2a)). In the case of both cadastral and geobia objects (Figure 7(3)), or geobia objects only, a maximum of 12 Hot Spots are extracted-6 inside the roof envelope, and 6 along its 1 pixel wide perimeter-(Figure 7(5)), along with their related geo-spatial statistics (Figure 7(6)). Conversely, with the use of cadastral house polygons, the Hot Spot algorithms go through an iterative process (Figure 7(4)) of refining each GEOBIA object based on its fit to its corresponding pre-existing house polygon, before identifying Hot Spots. This iterative refinement procedure was initially created to ensure a strong visual agreement between GEOBIA and cadastral house 'objects' (typically $>80 \%$ ) due to the high-order polynomial warping required during geocorrection of the original TABI-320 image (Section 2). 
Figure 7. The Hot Spot processing flow-diagram, showing paths for both raster and vector data.

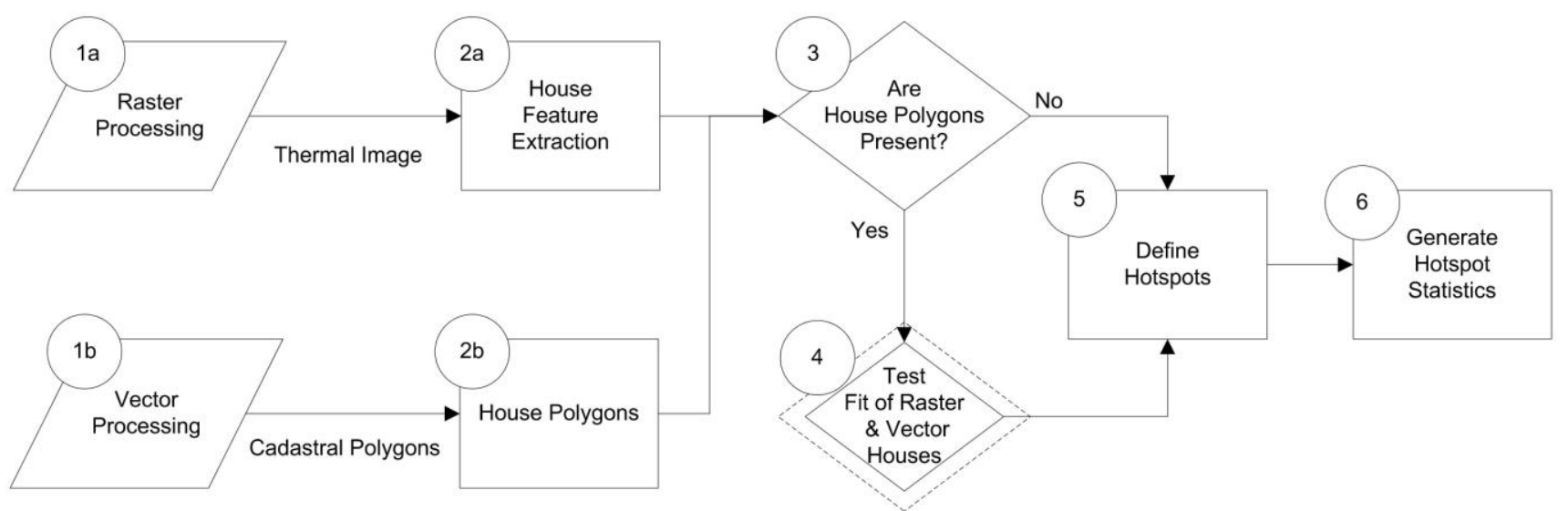

When large discrepancies are detected between the geobia defined houses and the cadastral houses the resulting objects are flagged for further investigation and manual verification by an analyst. Along with this flag, many other statistics are calculated for all geobia houses, which may further be used in KDD (Knowledge Discovery from Databases) and data mining [34]. Figure 8(A) illustrates a 79.4\% agreement between the GEOBIA roof object (center green) derived from the TIR image, and the corresponding City polygon (center red) derived from a manually digitized color aerial ortho-photo-mosaic. Figure 8(B) shows the Hot Spots (red dots) constrained within the GEOBIA object boundaries, and (Figure 8(C)) shows three corresponding circular Hot Spots located on a colorized waste heat image (blue is cold, red is hot). The minimum distance between Hot Spot locations is pre-defined by an analyst (i.e., 2-4 pixels apart), so that a clustering effect does not visually occur in the image; which due to the limited number of Hot Spots able to be shown at a single time (i.e., 3 out of 6), could result in other more spatially distributed (and useful) Hot Spot locations being missed.

Figure 8. An example of (A) the fit between geobia (green) and cadastral (red) house objects, (B) their associated Hot Spots (red dots), and (C) how these Hot Spots appear on the thermal image. Hot Spot are thermally ranked from hottest to coldest (red, orange, yellow), and displayed three at a time (see Figure 5(B)).

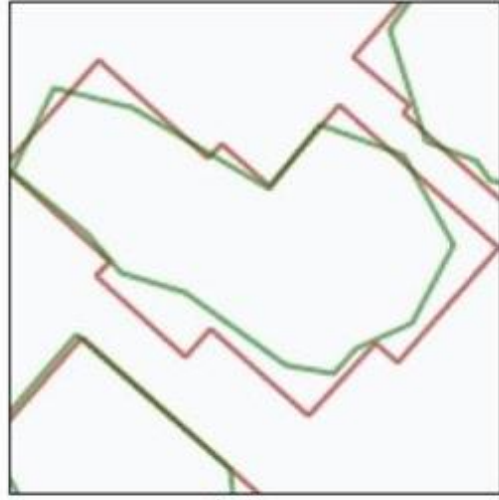

(A)

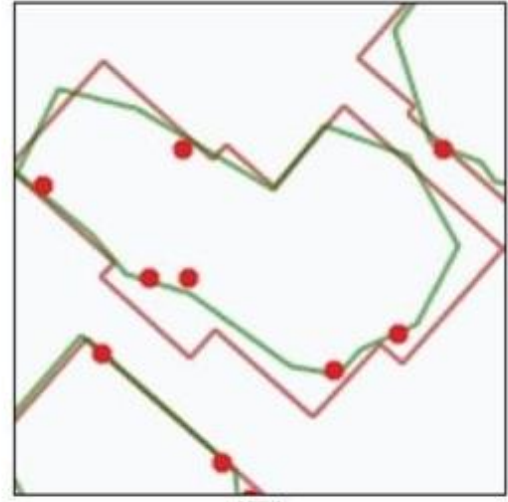

(B)

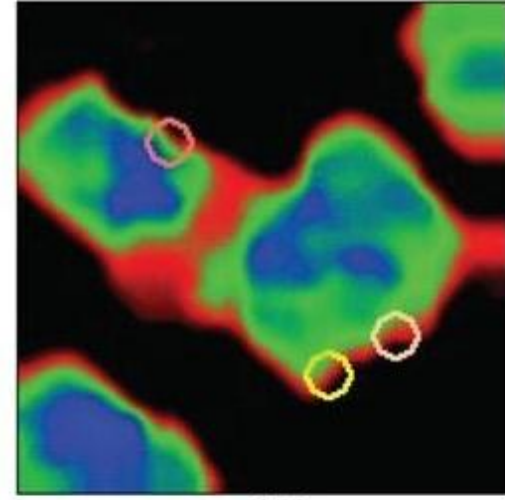

(C) 


\subsection{The HEAT Score Algorithm}

Numeracy - the ability to reason with numbers and other mathematical concepts - is applied in decision support and risk analysis assessments, where either hard, or easy to evaluate attributes are provided to users, to examine their influence on user preferences [35]. The rule of thumb from numerous studies is essentially, '...that numbers matter...' and that when given a choice, “...subjects typically prefer larger numbers, than smaller numbers..." (see Section 4.5 for details). In a related Geoweb example, the Walk Score website (www.walkscore.com/) provides a walk ability measure for 'any' North American home address based on a number of estimated factors, such as distance to schools, shopping, healthcare, etc. Results show that this single Walk Score value (defined out of 100) also has important implications for the real-estate market, where one point of Walk Score is worth up to $\$ 3,000$ of property value to that home [36].

In order to meaningfully compare the waste heat of one or more houses with all other houses in the city, we have developed a normalized HEAT Score based on the z-score or standardized score [37]. A standard score indicates how many standard deviations an observed value, (in this case the average roof top temperature), is above or below the population mean. For our HEAT Score, this represents the average of all the average roof top temperatures in the city. Similarly, our population represents all the houses in the city, or more specifically all the houses in the Brentwood community dataset. Based on the standard score formula (Equation (4)) the HEAT Score is calculated as shown in Equations (5) and (6):

$$
\text { [z-score }=(x-\mu) / \sigma]
$$

$x$ is the average roof top temperature to be standardized, $\mu$ is the average of all the average roof top temperatures in the city, and $\sigma$ is the standard deviation of the average roof top temperatures in the city. Z-scores follow a standard normal distribution; consequently 99.98 percent of the values will lie between -3.49 and 3.49. In our case, this z-score is proportionately converted to a scale from 0 to 100 , to represents the HEAT Score for every home.

$$
\text { HEAT Score }=(\mathrm{z} \text {-score of an item }-(-3.5)) /(3.5-(-3.5) \times 100)
$$

$$
\text { HEAT Score }=(\mathrm{z} \text {-score }+3.5) / 7 \times 100
$$

In Equations (5) and (6), the value of 3.5 is used instead of 3.49 to provide a buffer so that we can include $0.02 \%$ (100-99.98) of the values which might occur in this distribution. By using this HEAT score an individual can compare their house, with any other house in any part of the city. In simple terms, if the HEAT Score for a home is $91 \%$ it would indicate that "...this home wastes more HEAT than $91 \%$ of the other homes in this city". Associated with each HEAT Score would also be a relative descriptor, which for $91 \%$ would state “...Very High Waste HEAT...” Additional examples are shown in Table 2. The City HEAT Score is calculated based on the average HEAT Score of all houses in the City (see Figure 3), while the Community HEAT Scores are calculated based on the average HEAT Score for all the houses in each community (see Figure 4). 
Table 2. HEAT Score ranges and relative descriptors.

\begin{tabular}{|c|c|}
\hline Heat Score & Relative Descriptor \\
\hline $90-100$ & Very high \\
\hline $75-89$ & High \\
\hline $50-74$ & Moderately High \\
$25-49$ & Moderately Low \\
\hline $10-24$ & Low \\
\hline $0-9$ & Very Low \\
\hline
\end{tabular}

\section{Discussion—Challenges, Lessons, Solutions}

In this section we discuss critical challenges we still face, lessons learned, and briefly describe proposed solutions that we are currently working on for Phase II of the HEAT project, as we scale from 368 to 300,000+ homes and begin using TABI-1800 data. Specifically we will: (i) discuss Phase I limitations with the TABI-320 for large urban areas, and propose a TABI-1800 solution; (ii) introduce a new Object-Based Mosaic algorithm that solves the problem of bifurcated roof/house objects along the mosaic seam; (iii) propose Emissivity Modulation to convert the image to true temperatures; (iv) introduce Thermal Urban Road Normalization (TURN), a new object-based method to correct for local climatic variability during data acquisition; (v) discuss concerns with the HEAT Scores and describe how to implement a Carbon Score; and (vi) provide an example where errors in the City's cadastral database could be corrected from a combination of GEOBIA (feature detection) and TABI data.

\subsection{TABI Acquisition Limitations and Solutions}

The small footprint of the TABI-320 makes it well suited for narrow-width long-transect data acquisitions such as along transmission- and pipe-lines, but impractical for acquiring large area urban datasets. For example, to image the entire city of Calgary $(24 \times 35 \mathrm{~km}) \approx 160 \mathrm{flight}$ lines would need to be collected over 15 days at a cost of $\approx \$ 150 \mathrm{~K}+$ (CAD: based on a 2009 ITRES acquisition quote). Additionally, serious thermal calibration problems would undoubtedly arise due to weather differences over such a long acquisition time (see Haringey TIR acquisition in Section 1). To overcome these challenges, we suggest that the solution for future large-area high-resolution urban thermography data acquisitions will be found with the new TABI-1800 [38].

The TABI-1800 has a swath width of 1,800 pixels, and ability to collect up to $175 \mathrm{~km}^{2}$ per hour at $1.0 \mathrm{~m}$ spatial resolution. This is three to five times larger and faster than most other airborne TIR sensors. The TABI-1800 calculates radiometrically calibrated and geo-referenced data when in the air and uses diffraction-limited optics to ensure spatial independence of each pixel to avoid smearing between pixels. The Stirling Cycle cooled MCT (mercury cadmium telluride) detectors are four times faster than the non-cooled ones used in most TIR sensors, thus allowing for the rapid detection of much weaker thermal signals (i.e., thermal resolution $0.05{ }^{\circ} \mathrm{C}$ ), while diminishing thermal drift as compared to bolometer-based systems [38]. We note that on 31 March 2011 (between 24:00 and 4:45 hrs MST), twenty three $35 \mathrm{~km}$ long flight lines were acquired by the TABI-1800 over the City of 
Calgary Alberta in its maiden acquisition. The resulting dataset were acquired at a $70 \mathrm{~cm}$ spatial resolution in just over $4.5 \mathrm{hrs}$ total flight time on a single fuel tank (Navajo platform), at about $1 / 4$ the cost of the TABI-320. No other TIR system currently exists like this anywhere in the world. Lessons learned from working with the TABI-320 in Phase I of the HEAT project will be applied to this new dataset in Phase II, to create evidence based geoinformation to facilitate enhanced energy efficiency decisions for some $300,000+$ Calgary homes, with plans to apply worldwide.

\subsection{Object-Based Mosaicing (OBM)}

The TABI-320 scene is composed of two flight lines that are mosaiced with a $30 \%$ overlap between each flight line [39]. Due to geometric and radiometric variations (in this case primarily from microclimatic thermal variability) during different acquisition times, similar objects may have different spectral characteristics within and between flight lines [40]. In the TABI-320 dataset, this temporal difference is most apparent where the mosaic seam divides one or more house objects, resulting in different temperatures for each portion of the affected house; which in turn incorrectly biases temperature based statistics (Table 2). In the recently collected TABI-1800 dataset there are 23 flight lines, (each $35 \mathrm{~km}$ long), sampling a city of $300 \mathrm{~K}+$ homes. Thus, potential exists for many thousands of roof objects to be affected, and incorrectly assessed. To mitigate this condition, we propose a new GEOBIA method referred to as Object-Based Mosaicing (OBM) (Figure 9) and describe the pseudo code to incorporate only whole roofs within the mosaic process. In all cases we assume that each flight line has previously been geometrically corrected by the data provider with a spatial error of \pm 2 pixels (or less).

\subsubsection{OBM Pseudo Code}

- In the case where cadastral polygons exist, each flight needs to be geometrically corrected to the corresponding roof-top polygons.

- In the case where only thermal data exists, object-based feature detection will be applied to each flight line (separately) to extract roof-top polygons.

- A suitable sized buffer around each roof [e.g., 2-3 times the reported geometric correction error (in pixels)] needs to be generated to compensate for unresolved local geometric errors between flight lines.

- For two adjacent flight lines, the overlap between each flight line will be defined, from which a linear center mosaic line will be defined (yellow line in Figure 9).

- The buffered roofs that are divided by the flight line will be identified.

- Based on the proximity of each bifurcated roof to the center of its flight line (so as to reduce radial displacement effects) the center mosaic line will be joined around defined roof buffers (red line Figure 9), and used to mosaic adjacent datasets together.

- This process is then applied to the next adjacent flight line and repeated until all flight lines are mosaiced. 
Figure 9. A graphic of two flight lines (pink and blue), with a $30 \%$ overlap (purple) are shown along with an example of the resulting object-based mosaic line (red) derived from a joining of the initial mosaic line (yellow) and the buffered (blue) roof-top objects (grey).

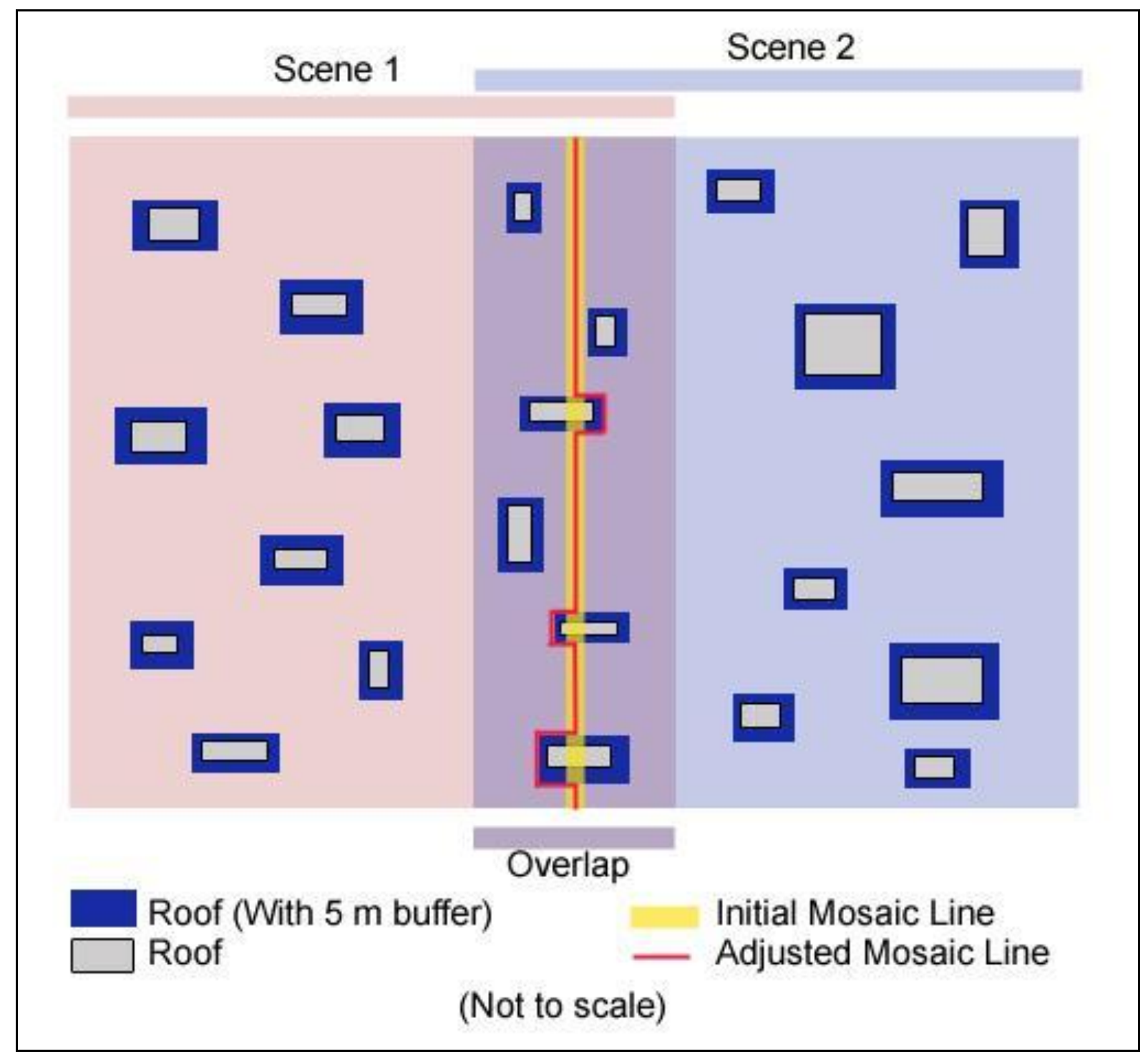

\subsection{Emissivity Modulation (EM)—Correcting for Emissivity}

Defining Hot Spots does not require the TABI data to be converted to true temperatures, because we search only within a single roof object, and we assume that based on its $1.0 \mathrm{~m}$ spatial resolution in comparison to the (much smaller) sized objects typically found on a roof (e.g., vents), that the roof material is essentially homogenous. Thus any difference in roof temperature is due to thermal conductance from the (lower) living envelope. However, if the spatial resolution of the TABI data were closer to $0.25 \mathrm{~m}$ then individual pixels would be more representative of (plastic and metal) vents and other objects found on the roof; which would require solving the emissivity for each material type. In the Phase I situation, spatial scale (considered as pixel size) reduces the thermal complexity of roof materials. However, if we develop energy models based on differences between the maximum and minimum roof temperatures for each roof, and we compare those results with different roofs to create a HEAT Score, then we need to first correct for different roof materials. 
Early attempts have been made to quantify the impact of emissivity on estimating the true kinetic temperature from remote sensing imagery. The simplest method used by researchers was to integrate the thermal data with the corresponding land use data [41,42]. Similarly, Savelvev and Sugumaran [43] collected ground truth data (i.e., radiant temperature) of objects with known emissivity, which were then integrated with Planck's Law [44] to develop an empirical regression model for calculating the true kinetic temperature of image pixels. Recently, the Emissivity Modulation technique [45] was proposed to perform spatial enhancement and emissivity correction of ASTER $(90 \mathrm{~m})$ thermal bands using a higher resolution optical image (ASTER $15 \mathrm{~m}$ ). For this study, we propose to apply the Emissivity Modulation technique to the $1.0 \mathrm{~m}$ TABI-320 using a $1.0 \mathrm{~m}$ RGB airphoto (resampled from our existing $30 \mathrm{~cm}$ RGB airphoto). To the best of our knowledge this has never been applied to such an H-res dataset. This method is expected to increase accuracy in the computation of kinetic temperature, improve the relationship between image values and air temperature, and better enable the observation of microscale temperature patterns [45]. If successful, we will also apply this procedure to the new TABI-1800 dataset.

\subsection{Thermal Urban Road Normalization (TURN)_Correcting for Local Climatic Variability}

Thermal remote sensing is strongly influenced by local microclimatic variability [46] of which the main components are wind, precipitation, and humidity. (i) Surface winds increase convective heat loss from ground objects and make them cooler [47]. (ii) Precipitation forces objects to cool down and to achieve a uniform temperature state [48], and (iii) as the humidity increases, ground targets appear to be cooler [46]. Thus, objects of similar thermal state but placed in varied microclimatic conditions will exhibit different temperature measurements from thermal remote sensors.

The importance of modeling local climatic variability to reveal surface temperature is described by Voogt and Oke [5] and others [46,49]. However, to the best of our knowledge, we have found no urban thermal study that considers the influence of local climatic variability on remote sensor observation. This may be explained because local climate variables differ dramatically within very small spatio-temporal scales. Consequently, it is difficult to develop models to predict such variations. Additionally, in the past the availability of high-resolution TIR data for large urban areas has been limited [50]. In the case of airborne TIR imagery, the ambient sensed temperature also naturally changes during, and between flight line acquisitions, resulting in mosaiced images with different temperatures for the same (overlapping) scene components, making detailed analysis non-trivial (see Section 4.2).

In an effort to minimize the effects of local microclimatic variability from different flight paths, we briefly introduce the Thermal Urban Road Normalization (TURN) algorithm, which is based on the idea of pseudo invariant features, such as roads or highways (i.e., concrete, gravel, tar) which during TIR acquisition are expected to be at a constant scene temperature (see roads in Figure 1). Thus, any variation observed in (average) road temperature throughout the scene is assumed to be the effect of local climate variation; which we suggest is a valid assumption for acquisitions late at night, or early in the morning in northern winter climates. Essentially the TURN model will calculate deviations from average road temperatures and will then adjust the temperature of the entire image, based on an interpolation of mean-deviation temperatures between roads. 


\subsubsection{TURN Pseudo Code}

The pseudo code for creating TURN is described as follows:

- Begin by isolating roads of a common material type either from an available GIS road layer, or using GEOBIA methods to segment and define specific road types in the TIR image.

- A $1.5 \mathrm{~m}$ buffer will then be created around each side of the road center (thus $3.0 \mathrm{~m}$ total diameter) to remove sidewalks, parked vehicles, curb side drains etc., or in the case of segmented roads, the mathematical morphology function erosion can be applied until a $3.0 \mathrm{~m}$ road skeleton remains.

- The remaining road object will then be emissivity corrected for material types (i.e., concrete, gravel, tar) to generate a 'kinetic' or 'true' temperature 'road' object.

- A random sample will extract $20 \%$ of these 'true' road pixels for an accuracy assessment, while the mean of the remaining $(80 \%)$ road pixels will be calculated.

- The mean temperature deviation per unit temperature for each 'true-road' pixel will then be calculated.

- The mean deviation will be interpolated over the entire image using three different interpolation methods: (i) Ordinary Kriging; (ii) Inverse Distance Weighting; and (ii) Splines.

- The temperature of all scene pixels will then be adjusted with the mean deviation values.

- An accuracy assessment will be performed for the three interpolation methods separately using the extracted (20\%) road pixels. It is expected that the model will generate average road temperatures for each road pixel. Any deviation from the average temperature will be considered as an error (due to microclimatic variation).

- The RMSE will then be calculated for each interpolation method, and their accuracies will be compared.

- The resulting normalized image with the lowest RMSE and most visually meaningful results will then be used for further analysis.

\subsection{HEAT and Carbon Scores}

A concern with the current HEAT Score is that intuitively, higher scores are generally considered 'better' than lower scores (Section 3.4). In its current state, the higher the HEAT Score, the greater the waste heat generated by the home. However, we do not want to 'celebrate', 'support' or 'promote' high waste heat, but rather the opposite. Unfortunately, a simple reversal of the algorithm, where a low wasteheat score represents a high HEAT Score, does not make sense. Furthermore, as currently calculated, the HEAT score cannot be used to compare houses in different cities. In order to allow for intra-city waste heat competitions, this will need to be solved, but as we currently do not have additional data, this is relegated to future work. In the meantime we are currently developing a 'Carbon Score'. This is based on the Fuel Table (Section 3.2.4) calculations for each home, which are weighted by livable house area, and the estimated $\mathrm{CO} 2 \mathrm{e}(\mathrm{kg})$ from the fuel type used [1,31]. Similar to the existing Community and City HEAT maps, we will also generate classified Carbon Maps to spatially model 'carbon' distribution associated with home/community/city energy usage. 


\subsection{Updating Cadastral Errors with GEOBIA and Thermal Imagery}

The automated GEOBIA approach to house extraction from the TABI-320 data has shown unexpected positive results by automatically 'flagging' houses with house boundary digitizing errors from the city cadastral vector dataset (on the order of 6\%). If this error relationship holds valid for the entire 300,000+ homes located in Calgary, this represents a potential of some 18,000+ home boundaries incorrectly recorded within the official cadastral record. The probability that the same kind of errors exist in other cities is also high. Thus, potential exists for this thermal-based house boundary information to be provided as a commercial product to interested municipalities. At present this relationship has not been verified over a larger sample, however, our intention is to further examine this in the TABI-1800 scene, and to evaluate interest from the city for related geoinformation products. In the Brentwood dataset, these $6 \%$ digitizing errors have been verified using the HEAT Google Street View functionality (see Figure 5) which allows for individual homes to be viewed from multiple angles, not just from a plan-view as in the Google satellite or aerial photography. For example, in Figure 10 a thermal sub-image (Figure 10(A)) reveals that a house and garage (in blue and green) are two separate entities, adjacent to a central 'hot' area (in red). In (Figure 10(B)) the cadastral house polygon defines both of these structures as a single house vector. Since the cadastral polygon is larger than the average size of the neighboring polygons, and does not perfectly agree with the area of the GEOBIA house object, it was automatically flagged for further visual analysis (see Section 3.3). (Figure 10(C)) Shows a corresponding $30 \mathrm{~cm}$ air photograph sub-image of the scene which visually appears to correlate with the cadastral polygon (Figure 10(B)); however a Google Street View perspective of this garage and house combination (Figure 10(D)), reveals that this manually drawn cadastral polygon is incorrect (as it failed to distinguish the temporary roof), but that the separate thermal house and garage structures (Figure 10(A)) are indeed correct.

\section{Conclusion}

With the primary goal to improve urban energy efficiency by developing geospatial technologies that provide effective user feedback, the HEAT pilot project is a FREE Geoweb mapping service designed to allow residents to visualize the amount, location and cost of waste heat leaving their homes and communities as easily as clicking on their house in Google Maps. HEAT incorporates geospatial solutions for residential waste heat monitoring using Geographic Object-Based Image Analysis (GEOBIA) and Canadian built Thermal Broadband Airborne Imager (TABI) technology to provide users with timely, in-depth, easy to use, location-specific waste-heat information; as well as opportunities to save their money and reduce their green house gas emissions. In this paper, we describe the HEAT Phase I pilot project which evaluates 368 residences in the Brentwood community of Calgary, Alberta, Canada. This FREE service: (i) defines the 6+ hottest locations on each home, and relates them to windows, doors, roofing, and/or insulation solutions from local service providers; (ii) automatically links each home to Google Street View to confirm Hot Spot locations; (iii) provides green house gas and space-heating estimates for different fuel types for each home; (iv) identifies the hottest homes in each community; and (v) provides a HEAT Score for comparative analysis and monitoring at the house, community and city scales. We also discuss lessons learned from Phase I as we prepare to scale to $300,000+$ homes (in Phase II) with the newly developed TABI-1800. 
Specifically, we introduce a new object-based mosaicing strategy, an adaptation of Emissivity Modulation to correct for emissivity differences, a new Thermal Urban Road Normalization (TURN) technique to correct for scene-wide microclimatic variation, and describe a new Carbon Score. We also show that a combination and TABI and GEOBIA feature detection could be used to update (a possible 18,000+) incorrect house polygons that potentially exist within the City Cadastral dataset.

Figure 10. A house and garage are shown as two separate entities in a TABI-320 sub-image $(1.0 \mathrm{~m})(\mathbf{A})$, while the cadastral house polygon $(\mathbf{B})$ defines them as a single house vector. (C) shows a corresponding air photograph $(30 \mathrm{~cm})$ of the scene which visually correlates with the cadastral polygon; however a Google Street View perspective (D), reveals that this cadastral polygon is incorrectly drawn, and that the thermal information is correct.

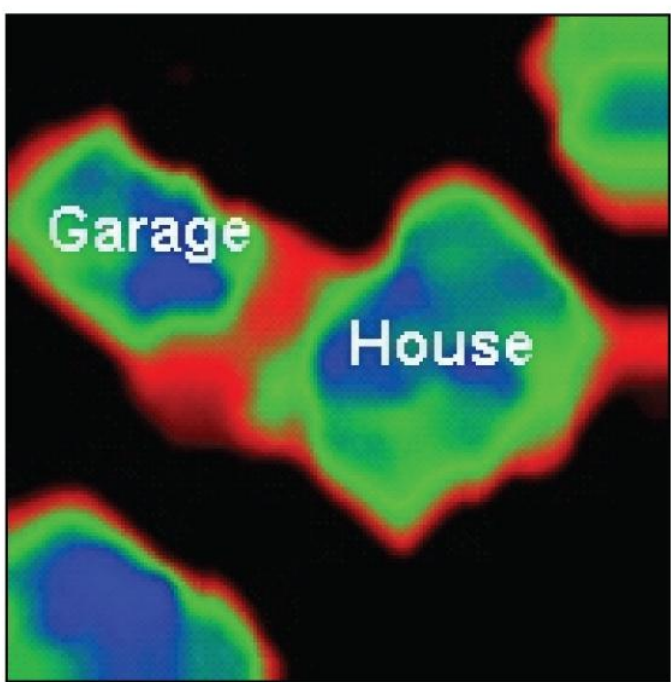

(A)

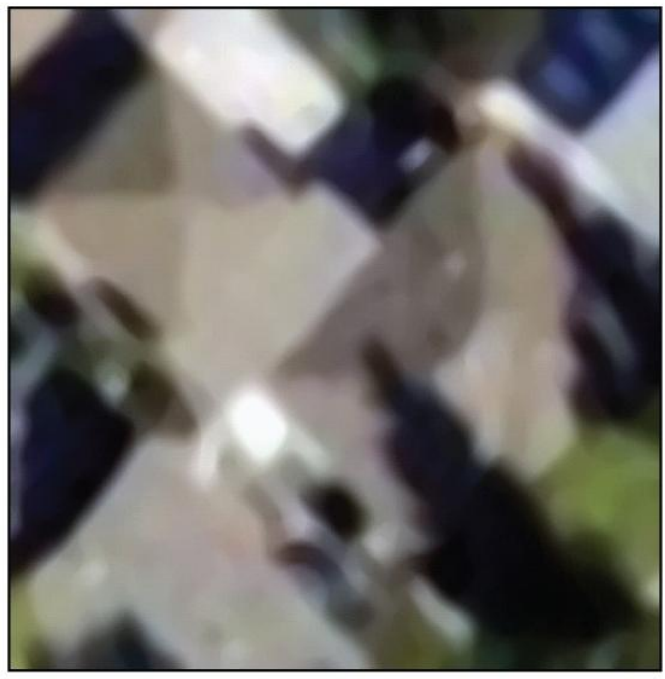

(C)

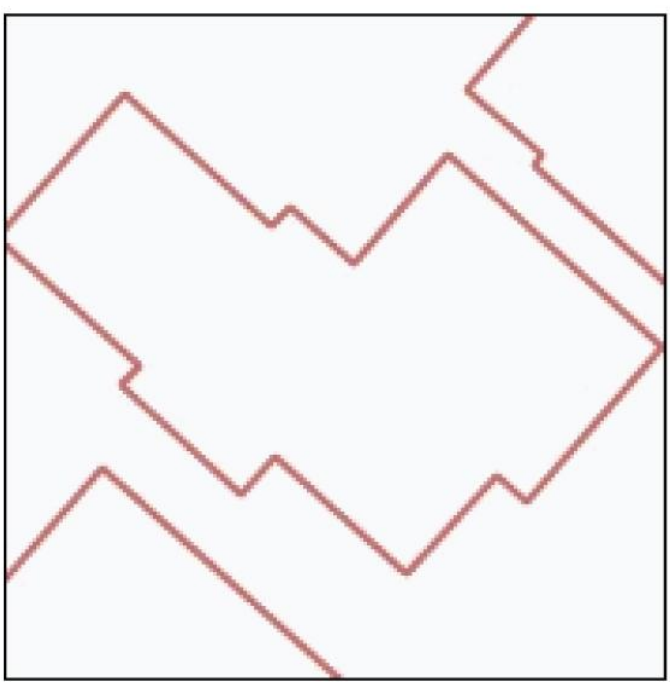

(B)

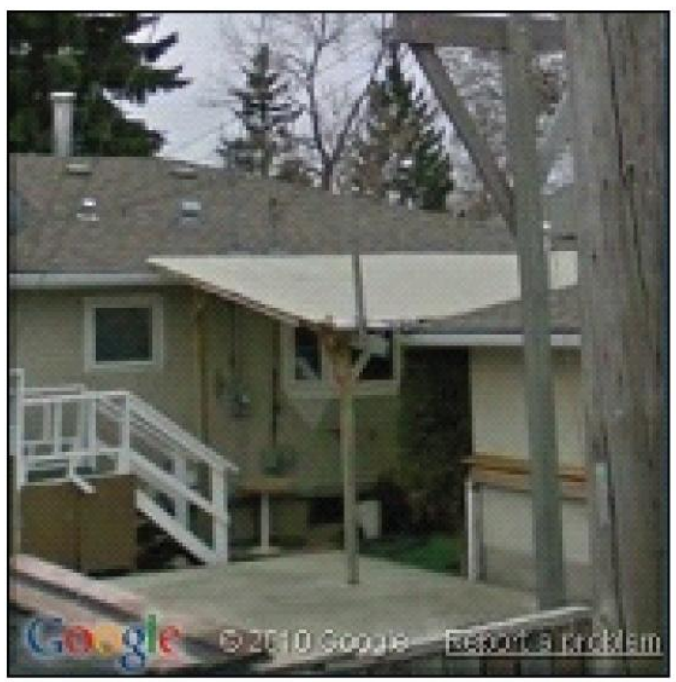

(D) 
Since these free energy-efficiency decision support tools provide information at the house, community and city scale, they may also: (i) provide service agencies evidence of successfully implementing energy retrofit programs; and (ii) opportunities to promote national and international intra- and inter-city waste heat competitions. Additionally (iii) renovation contractors may find these tools useful for identifying neighborhoods for marketing energy efficiency upgrades, or (iv) residential service providers offering energy efficiency solutions. (v) Construction companies could also use these results to verify the energy-efficiency quality of their homes, and (iv) real estate agents, could use them to assist energy conscious clients. Law enforcement agencies may also be able to (v) use this spatial intelligence for identifying energy theft, and (vi) illegal grow-ops. Additional uses may be found by (vii) municipal planners looking to identify the 'best' communities to focus energy efficiency incentives upon, and (viii) to support Government and municipal Energy Efficiency and Ecological Footprint programs.

HEATs mission is to show what urban energy efficiency looks like, where it is located, what it costs, and what to do about it. We believe that if people could see the waste heat they generate and if they knew how much it cost (from a $\$$ and environmental perspective), that they would want to take action. We want to show them how. Ultimately, our vision is to empower the urban energy efficiency movement by providing free, accurate and regularly updated TIR waste heat solutions for the world. To evaluate the current version of HEAT, please login to (http://www.wasteheat.ca) as beta, with the password beta (no italics).

\section{Acknowledgements}

Geoffrey Hay acknowledges critical support from The Institute for Sustainable Energy, Environment and Economy (www.iseee.ca), ITRES Research Limited (www.itres.com), the City of Calgary (www.calgary.ca), the Urban Alliance (www.urban-alliance.ca), the UofC Foothills Facility for Remote Sensing and GIScience (www.ucalgary.ca/f3gisci), the University of Calgary-ARTS Information Technologies Team (http://arts.ucalgary.ca/it/), The Tecterra GECKO program (www.tecterra.com) and NSERC (www.nserc.ca). We also acknowledge an Alberta Informatics Circle of Research Excellence (iCore) PhD Scholarship awarded to Gang Chen, and a University of Calgary Faculty Graduate Research Scholarship and a Geography Excellence Award provided to Mir Mustafizur Rahman. We also thank Ryan Powers for his early HEAT research contributions. The opinions expressed here are those of the authors, and may not reflect the views of their funding agencies.

\section{References}

1. CUI. Energy Mapping Study; Canadian Urban Institute: Toronto, ON, Canada, 19 December 2008; p. 92. Available online: http://www.calgary.ca/docgallery/BU/planning/pdf/plan_it/ energy_mapping_study.pdf (accessed on 1 April 2011).

2. Darby, S. The Effectiveness of Feedback on Energy Consumption; Report published by Environmental Change Institute; University of Oxford: Oxford, UK, 2006. Available online: http://www.eci.ox.ac.uk/research/energy/downloads/smart-metering-report.pdf (accessed on 1 April 2011). 
3. Marsden, G. Beyond Your Utility Meter: Three Energy Monitors for Your Toolbox. Home Power August/September 2010, 138, 54-58.

4. Google. A Letter to the President of the United States; 2010. Available online: https://sites.google.com/site/obamaenergyletter/home/ (accessed on 5 July 2011).

5. Voogt, J.A.; Oke, T.R. Thermal remote sensing of urban climates. Remote Sens. Environ. 2003, $86,370-384$.

6. Allinson, D. Evaluation of Aerial Thermography to Discriminate Loft Insulation in Residential Housing. Ph.D. Thesis, University of Nottingham, Nottingham, UK, 2007. Available online: http://etheses.nottingham.ac.uk/284/ (accessed on 1 April 2011).

7. Weng, Q. Thermal infrared remote sensing for urban climate and environmental studies: Methods, applications, and trends. ISPRS J. Photogramm. Remote Sens. 2009, 64, 335-344.

8. Stockton, G.R. Aerial infrared Thermagraphy. Cadalyst September 2004, 21, 47-53.

9. Jensen, J.R. Thermal Infrared Remote Sensing. In Remote Sensing of the Environment: An Earth Resource Perspective; Chapter 8; Prentice Hall: Upper Saddle River, NJ, USA, 2007; pp. 249-290.

10. Frost \& Sullivan. US Commercial and Military Infrared Imaging System Markets; Report A020-Pub.8; 2001.

11. Hay, G.J.; Hemachandran, B.; Kyle, C.D. HEAT (Home Energy Assessment Technologies): Residential waste heat monitoring, Google Maps and airborne thermal imagery. GIM Int. 2010, 3, $13-15$.

12. Council Claims Back Cash after 'Heat Map' Fails; 13 May 2010. Available online: http://www.portsmouth.co.uk/news/local/east-hampshire/council_claims_back_cash_after_heat_ map_fails_1_1251057 (accessed on 30 January 2011).

13. Clark, M.L; Aide, T.M. Virtual Interpretation of Earth Web-Interface Tool (VIEW-IT) for Collecting Land-Use/Land-Cover Reference Data. Remote Sens. 2011, 3, 601-620.

14. Geoweb. Available online: http://www.Geowebconference.org/ (accessed on 1 April 2011).

15. Digital Earth. Available online: http://en.wikipedia.org/wiki/Digital_Earth (accessed on 1 April 2011).

16. Pyxisinnovation. Available online: http://www.pyxisinnovation.com/ (accessed on 1 April 2011).

17. Hay, G.J.; Blaschke, T. Forward: Special Issue on Geographic Object-Based Image Analysis (GEOBIA). Photogramm. Eng. Remote Sensing 2010, 76, 121-122.

18. Ushahidi. Available online: http://vimeo.com/ushahidi (accessed on 1 April 2011).

19. Firemap. Available online: http://firefly.geog.umd.edu/firemap/ (accessed on 1 April 2011).

20. Hay, G.J.; G. Castilla. Geographic Object-Based Image Analysis (GEOBIA): A new name for a new discipline? In Object-Based Image Analysis: Spatial Concepts For Knowledge-Driven Remote Sensing Applications; Blaschke, T., Lang, S., Hay, G.J., Eds; Chapter 1.4; Springer-Verlag: Berlin, Germany, 2008; pp. 75-89.

21. TABI-320. Available online: http://www.itres.com/products/imagers/tabi320 (accessed on 1 April 2011).

22. Jacob, F.; Francois, P.; Schmugge, T.; Vermote, E.; French, A.; Ogawa, K. Comparison of Land Surface Emissivity and Radiomatric Temperature Derived from MODIS and ASTER. Remote Sens. Environ. 2004, 90, 137-152. 
23. Parker, D.S.; McIlvaine, J.E.R.; Barkaszi, S.F.; Beal, D.J.; Anello, M.T. Laboratory Testing of the Reflectance Properties of Roofing Material; FSEC-CR-670-00; Florida Solar Energy Center: Cocoa, FL, USA, 2000.

24. Steiniger, S.; Hay, G.J. Free and Open Source Geographic Information Tools for Landscape Ecology: A Review. Ecol. Inf. 2009, 4, 183-195.

25. GNU Data Language. Available online: http://gnudatalanguage.sourceforge.net/ (accessed on 21 June 2011).

26. Segmentation Evaluation. Available online: http://www.ioer.de/segmentation-evaluation/ index.html (accessed on 21 June2011).

27. Neubert, M.; Herold, H.; Meinel, G. Assessing image segmentation quality-Concepts, methods and application. In Object-Based Image Analysis: Spatial Concepts for Knowledge-Driven Remote Sensing Applications; Blaschke, T., Hay, G., Lang, S., Eds.; Lecture Notes in Geoinformation \& Cartography; Springer: Berlin, Germany, 2008; pp. 769-784.

28. Allen, T.F.H.; Starr, T.B. Hierarchy Perspective for Ecological Complexity; University of Chicago Press: Chicago, IL, USA, 1982; p. 310.

29. Cressie, N. The Origins of Kriging. Math. Geology 1990, 22, 239-252.

30. Jenks, G.F. The Data Model Concept in Statistical Mapping. Int. Yearbook Cartogr. 1967, 7, 186-190.

31. The Urban Archetypes Project. Community Case Study: The City of Calgary; Canmet ENERGY Cat. No. M154-15/3-2009 E-PDF; CanmetENERGY: Ottawa, ON, Canada, 2009; p 10. Available online: http://canmetenergy-canmetenergie.nrcan-rncan.gc.ca/eng/publications.html?Cat.\%20 No.\%20M154-15/3-2009E-PDF\%20\%28On-line\%29\%20\%20\%20ISBN\%20978-1-100-11950-2 (accessed on 1 April 2011).

32. NetZero Buildings. Available online: http://en.wikipedia.org/wiki/Zero-energy_building (accessed on 1 April 2011).

33. LEED. Available online: http://en.wikipedia.org/wiki/Leadership_in_Energy_and_ Environmental_Design (accessed on 1 April 2011).

34. Piatetsky-Shapiro, G. Knowledge Discovery in Real Databases: A Report on the IJCAI-89 Workshop. AI Magazine 1991, 11, 68-70.

35. Wilson, R.S.; Arvai, J.L. When Less is More: How Affect Influences Preferences When Comparing Low and High-risk Options. J. Risk Res. 2006, 9, 165-178.

36. Walkscore value. Available online: http://blog.walkscore.com/2009/08/new-study-shows-onepoint-of-walk-score-worth-up-to-3000/ (accessed on 31 March 2011).

37. Z-score. Available online: http://en.wikipedia.org/wiki/Standard_score (accessed on 1 April 2011).

38. TABI-1800 Product Information. Available online: http://www.itres.com/products/imagers/ tabi1800/ (accessed on 1 April 2011).

39. Afek, Y.; Brand, A. Mosaicking of Orthorectified Aerial Images. Photogramm. Eng. Remote Sensing 1998, 64, 115-125.

40. Tuominen, S.; Pekkarinen, A. Local radiometric correction of digital aerial photographs for multi source forest inventory. Remote Sens. Environ. 2004, 89, 78-82. 
41. Balling, R.C.; Brazell, S.W. High Resolution Surface Temperature Patterns in a Complex Urban Terrain. Photogramm. Eng. Remote Sensing 1988, 54, 1289-1293.

42. Weng, Q. A Remote Sensing-Gis Evaluation of Urban Expansion and Its Impact on Surface Temperature in the Zhujiang Delta, China. Int. J. Remote Sens. 2001, 22, 1999-2014.

43. Savelyev, A.; Sugumaran, R. Surface Temperature Mapping of the University of Northern Iowa Campus Using High Resolution Thermal Infrared Aerial Imageries. Sensors 2008, 8, 5055-5068.

44. Rybicki, G.B.; Lightman, A.P. Radiative Process in Astrophysics; John Wiley and Sons: New York, NY, USA, 1979.

45. Nicole, J.E. An Emissivity Modulation Method for Spatial Enhancement of Thermal Satellite Images in Urban Heat Island Analysis. Photgramm. Eng. Remote Sensing 2009, 75, 1-10.

46. Hartz, D.A.; Prashad, L.; Golden, J.; Brazel, A.J. Linking Satellite Images and Hand Held Infrared Thermography to Observe Neighborhood Climate Conditions. Remote Sens. Environ. 2006, 104, 190-200.

47. Santamouris, M.; Papanikolaou, N.; Livada, I.; Koronakis, I.; Georgakis, A.; Assimakopoulos, D.N. On the Impact of Urban Climate on the Energy Consumption of Buildings. Solar Energy 2001, 70, 201-216.

48. Giannini, A.; Saravanan, R.; Chang, P. Oceanic Forcing on Sahel Rainfall on Interannual to Interdecade Time Scales. Science 2003, 302, 1027-1030.

49. Weng, Q.; Lu, D. A Sub-Pixel Analysis of Urbanization Effect on Land Surface Temperature and Its Interplay with Impervious Surface and Vegetation Coverage in Indianapolis, United States. Int. J. Appl. Earth Obs. Geoinf. 2008, 10, 68-83.

50. Pu, R.; Gong, P.; Michishita, R.; Sasagawa, T. Assessment of Multi-Resolution and Multi-Sensor Data for Urban Surface Temperature Retrieval. Remote Sens. Environ. 2006, 104, 211-225.

(C) 2011 by the authors; licensee MDPI, Basel, Switzerland. This article is an open access article distributed under the terms and conditions of the Creative Commons Attribution license (http://creativecommons.org/licenses/by/3.0/). 